\title{
Utilizations of food waste as an anaerobic digester feedstock
}

\author{
Krishna Kumar, Omprakash Sahu* \\ Department of Chemical Engineering, KIOT, Wollo University, Ethiopia
}

Email address:

ops0121@gmail.com(O.Sahu)

\section{To cite this article:}

Krishna Kumar, Omprakash Sahu. Utilizations of Food Waste as an Anaerobic Digester Feedstock, Journal of Energy and Natural Resources. Vol. 2, No. 1, 2013; pp. 1-7. doi: 10.11648/j.jenr.20130201.11

\begin{abstract}
For many years, anaerobic digestion has been utilized in order to treat the odorous, pathogenic, and dissolved-oxygen-reducing-characteristics of both anthropogenic and livestock effluent waste streams. In addition to this beneficial biological treatment, such digestion provides both methane gas and digestate which serve as a valuable fuel and fertilizer, respectively. However, food waste also has the potential to serve as a useful feedstock for anaerobic digestion due to its high volatile (combustible) solids content and propensity for rapid biodegradation. There are a number of parameters of concern when using food waste for such digestion which increases the operation complexity of digester systems, but if such devices are properly monitored and adjusted, food waste has the potential to serve as a sole feedstock or as part of a dual manure-food waste input; both cases provide an improvement in gas generation production.
\end{abstract}

Keywords: Bacteria, Decompositions, Decay, Methane

\section{Introduction}

In order to fully understand the advantages and disadvantages in the different feedstock used for anaerobic digestion (AD), it is necessary to understand the biology and variables inherent in organic matter decomposition and decay. Towards this end, the different bacterial regimes involved in $\mathrm{AD}$ will be discussed, as well as how the particular characteristics of food waste may enhance or disrupt microbial function. The unique considerations necessary for the use of food waste as a feedstock will be elaborated on. Next, both the financial aspects of food waste digestion, as well as the environmental benefits resulting from the diversion and biodegradation of food remains from the municipal waste stream will receive attention. Also, the applicability of using food waste as a feedstock in developing countries will be analyzed from a technical expertise and resource perspective, using Haiti as an example. Finally, a few examples of anaerobic food waste digestion systems will be reviewed as well as some of the challenges encountered during operations.

\section{Anaerobic Microbiology}

There are four stages in the breakdown of organic matter on the path to methane production; each stage is the result of a different bacterial subpopulation. These stages include hydrolysis, fermentation (or acidogenesis), acetogenesis and eventual methanogensis[1]. Hydrolysis involves the conversion of complex molecules and compounds carbohydrates, lipids and proteins - found in organic matter into simple sugars, long chain fatty acids and amino acids, respectively. Acidogenesis in turn converts these into volatile fatty acids, acetic acid, carbon dioxide and hydrogen gas. Acetogenesis converts the volatile fatty acids into more acetic acid, carbon dioxide and hydrogen gas. Methanogens have the ability to produce methane by using the carbon dioxide and hydrogen gas or the acetic acid produced from both the acetogenic or acidogenic phases. The Figure 1 for an overview of this decomposition process.

Some food wastes have a tendency to raise or lower the $\mathrm{pH}$ of digester solution, dependent upon the specific food remnants involved. Care must be taken to ensure that the digester liquid $\mathrm{pH}$ remains near neutral or at least between 6.7 and 7.4 so that the methanogens can survive[3]. When a bacterial food supply, or feedstock, is initially introduced into the digester, it is possible that the rate at which hydrolysis proceeds may overload the system with fatty acids thereby depressing the $\mathrm{pH}$ to the point of methanogenesis inhibition[4]. The often elevated levels of ammonia within manure feedstock usually serve as a buffer against drastic $\mathrm{pH}$ changes. This safeguard is also present in 
the anaerobic digestion of food waste when proteins are decomposed to form ammonia. This ammonia elevates levels of bicarbonate through the creation of ammonium salt by the removal of dissolved carbon dioxide from the digestion solution[5].

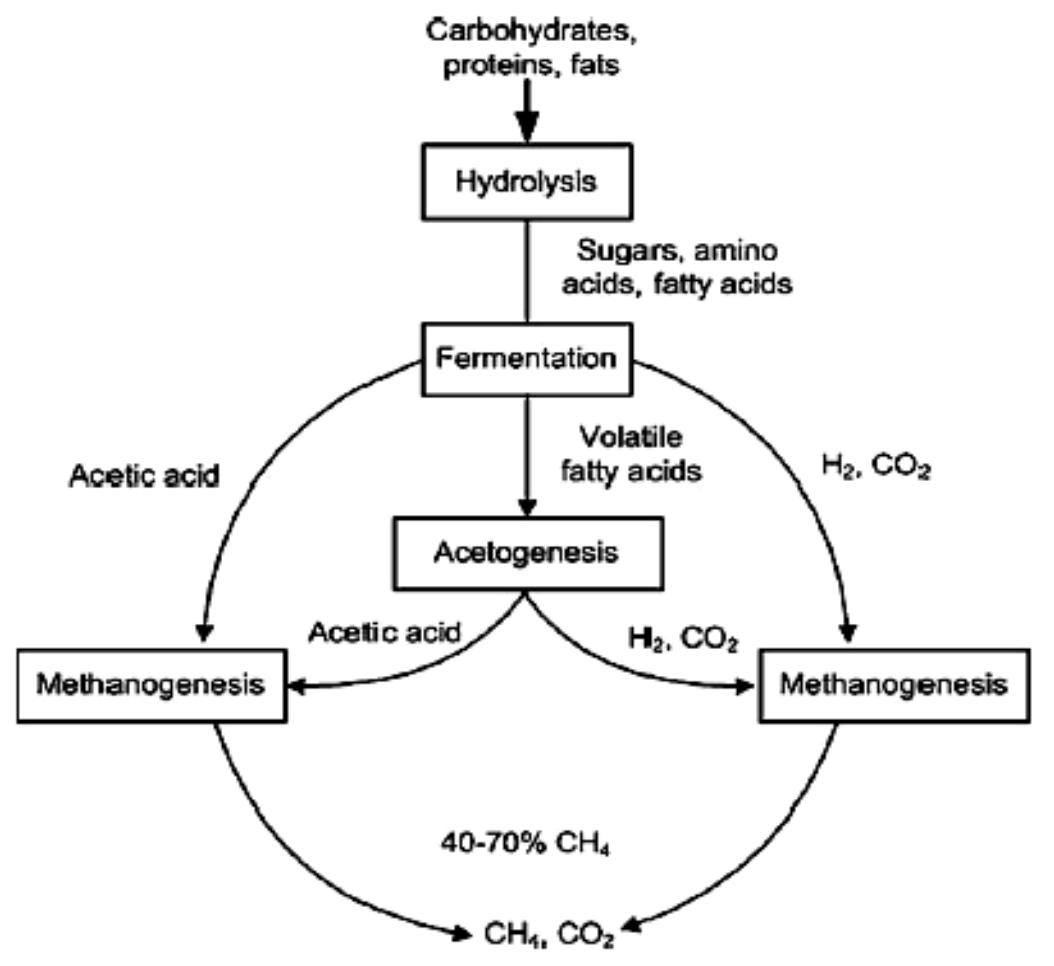

Figure 1. Stages of Anaerobic Digestion[2]

There are additional means of controlling the $\mathrm{pH}$ besides relying upon the inherent alkalinity. The possible depression of $\mathrm{pH}$ can also be avoided through control of volatile solids/organic loading, since in the first steps of the AD process these will be converted into volatile fatty acids. In a continuously-stirred tank reactor (CSTR) low-solids-content digestion system, it is typically recommended that the feedstock be diluted sufficiently so that the total solids (TS) concentration falls between $6 \%$ and $10 \%[6]$. In scenarios where the selected feedstock repeatedly decreases the $\mathrm{pH}$ to levels of concern, buffering agents including lime and/or sodium bicarbonate can be added to the digester. Unlike lime however, bicarbonate is advantageous insomuch as it does not have a tendency to form insoluble salts and is very unlikely to increase the $\mathrm{pH}$ outside the preferred range of methanogens. Also, it will not create a vacuum in the area over the digestion fluid, or headspace, due to the reaction with carbon dioxide[5].

\section{Unique Considerations to Using Food Waste Feedstock}

In assessing the feasibility of using food waste as a means of feeding anaerobes, it is important to note the specific characteristics which set it apart from manures and sludge. These include the increased likelihood of the presence of contaminants such as detergents and cleaners, nonbiodegradable components such as plastics and bones, and nonhomogenous-sized organic matter which will necessitate a form of size reduction. Each of these will require a form of pretreatment before food waste introduction into the digestion chamber(s). Furthermore, both human and animal sludge have one particular characteristic which gives them a unique advantage over food waste feedstock: a bountiful supply of anaerobes[7]. This is important because the initial loading of the digester with methanogens means a greatly reduced lag time between the previous acid generating stages and the methanogenic acid reducing stage. As a result, it is much less likely that the $\mathrm{pH}$ of the digester liquid will ever dip below the range preferred by the obligate anaerobes. In order to overcome these potential setbacks while using food waste for $\mathrm{AD}$, all kinds of equipment have been developed for both size reduction and contaminant removal. These can include devices such as trommel screens, hydrocyclones, pulpers/grinders, metal separators and flotation tanks. These devices are reliant upon the different densities and/or metal properties of the various contaminants and are usually able to remove the major undesirable portions of the food waste stream including plastics and grit. Figure 2 provides an example layout of a food waste AD in Korea showing the various pretreatment processes; this facility will be discussed in more detail later.

Perhaps one of the most desirable qualities of these 
digester systems is their ability to create useful gas energy with net-zero carbon emissions. But a reasonable question to ask when considering all these food-waste-specific pretreatment devices is whether or not there is actually a net energy gain. There is already energy input involved with both food and wastewater-solids-based AD systems due to the fact they are typically heated in order to maintain a constant operational temperature throughout the year. Digesters typically operate in either the mesophilic $\left(20^{\circ} \mathrm{C}-\right.$ $45^{\circ} \mathrm{C}$ ) or thermophilic range $\left(45^{\circ} \mathrm{C}-70^{\circ} \mathrm{C}\right)$, where the latter is generally preferred for its higher pathogen destruction and faster rates of gas production and solids degradation[9]. Whether or not an outside source of energy or power is used will depend on the particular plant arrangement. For the heating and power requirements could (and often do) draw a parasitic load on the combined heat and power (CHP) operations usually found at AD sites.

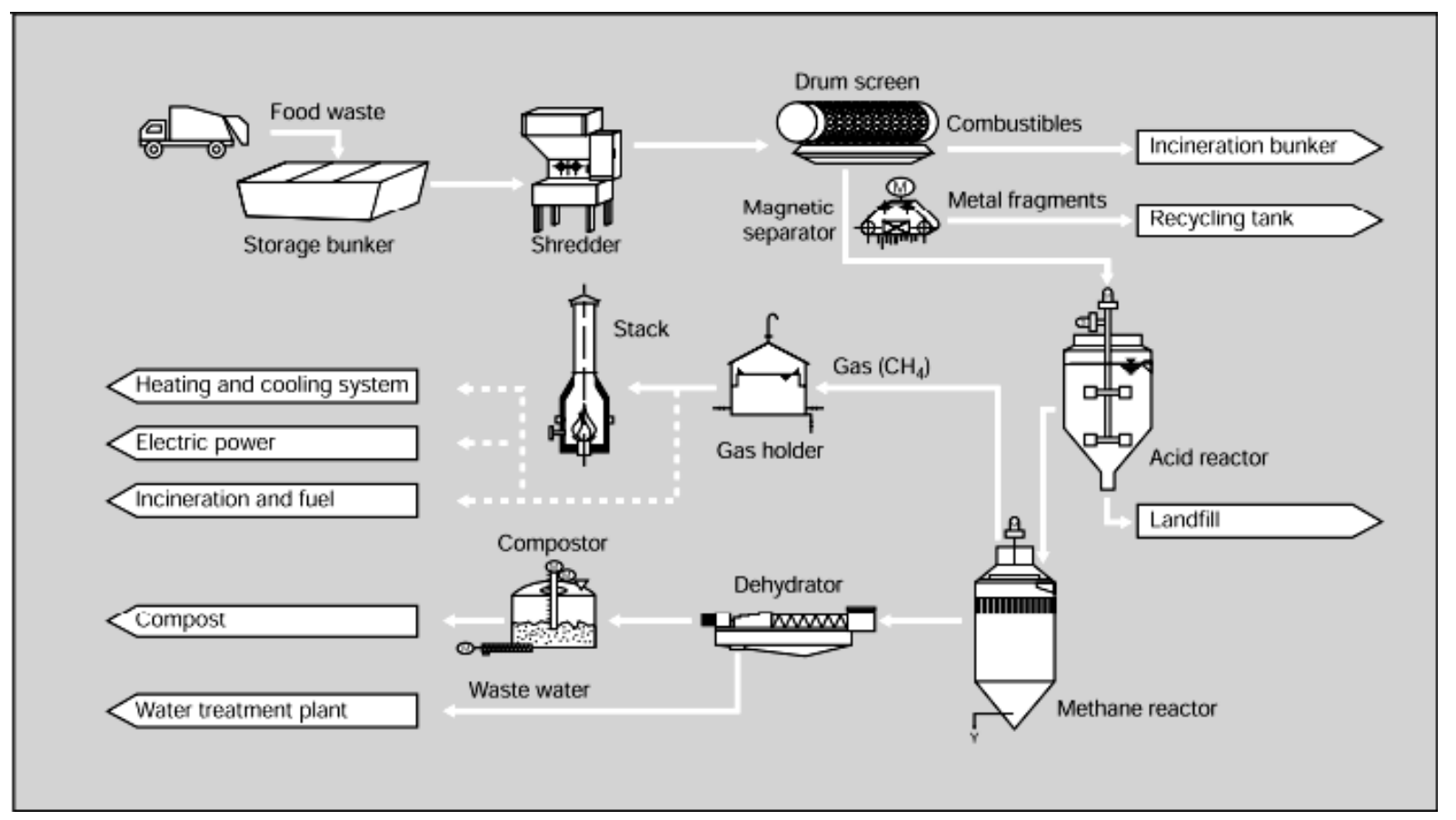

Figure 2. Operation Diagram of Food Waste Digester in Kombolcha[8]

\section{Financial Considerations}

In many cases, there are other recycling opportunities which will compete with food waste AD. These include using food wastes as either an animal feed or soil amendment through composting. As a result, from an economic perspective, the $\mathrm{AD}$ of food waste may not be the most financially sound option for its ultimate disposal. For example, Disney World through a company called Neutral Feed has been converting a significant portion of its food waste into animal feed, and the resulting product has even been approved by the United States Department of Agriculture for human consumption[10]. Due to the complexity of markets associated with the end-products of $\mathrm{AD}$, it is difficult to develop a solitary analysis which would be applicable to any individually proposed system. However, there are a number of factors of concern which should be analyzed for any planned AD construction which include facility space requirements, water demand, wastewater discharge quality and quantity, the quality and quantity of the digestate residual, local biogas markets, and electrical use and electricity production[11]. One such study was performed by a consulting firm, R.W. Beck, to determine whether or not an Iowa AD facility would be financially justifiable for incorporation into a solid waste agency's refuse management framework[9]. The methodology used in this study was to analyze a number of already existing facilities in Europe, since in 2004, the time of the study, no commercially operated facilities in the U.S. were using the organic fraction of municipal solid waste (OFMSW) for anaerobic digestion. R.W. Beck's sensitivity analysis showed that the present worth of the investment was most sensitive to the growth of the waste stream (feedstock) over a 20 year project horizon. However, some other important parameters analyzed included how much revenue would be gained from thermal and electric sales, as well as how much the facility could charge (while remaining competitive with other waste disposal options) for tipping fees.

R.W. Beck further provided an energy balance table which accounted for two energy inputs and outputs. Energy inputs included electricity and thermal energy. Energy outputs included methane and soil conditioner. Accepting that soil conditioner can be appropriately measured in terms of energy content, the table shows that digester produces roughly ten times the energy it consumes on an annual basis. This table appears to be a result of averaging the values from all the AD facilities surveyed across Europe. However, if 
this is the case, it is important to note that none of the facilities studied solely processed food waste, but rather typically processed OFMSW which, quite possibly, requires a more intensive pretreatment process due to a more variability within the waste stream. As a result, the electric cost estimated in this analysis is likely an overestimate.

The financial success of any food waste digestion enterprise will be highly dependent on the ability to acquire acceptable rates of revenue from carbon credits, sales of renewable energy back to local power utilities or private purchasers, and tax incentives. There are a number of different organizations which serve as an exchange for carbon credits, such as the California Climate Action Registry (CCAR). The CCAR currently lists a protocol for the digestion of organic waste which would apply to an AD facility for food waste which was attempting to earn carbon credits as a source of revenue[12]. These organizations will typically certify credits and allow their sale to companies who wish to offset their greenhouse gas (GHG) emissions. Different utility companies will often set rates at which they are willing to purchase renewably produced electricity, usually on a kilowatt-hour $(\mathrm{kWh})$ basis. Some states offer a $\$ / \mathrm{kWh}$ corporate state income tax credit. Florida, for example, currently offers a one cent credit per $\mathrm{kWh}$ produced by renewable means[13].

For stand-alone food waste AD plants (as opposed to co-digestion with wastewater solids at wastewater treatment plants), the amount of discharge water should be minimized to the greatest extent possible to reduce the resulting discharge wastewater treatment cost. There are a multitude of digester configurations which exist, but these can be broken into high $(>25 \% \mathrm{TS})$, medium $(10 \%-25 \% \mathrm{TS})$, or low solids models $(<10 \% \mathrm{TS})[14]$. It is clear that the waste stream most suitable for use in a food waste $\mathrm{AD}$ is one which will be highly controlled at the source. Different restaurant and food service industries have different degrees of processing and separation before waste removal occurs. Without this source separation/pretreatment, upfront processing will make up a large part of the operational costs incurred in $\mathrm{AD}$ of food waste.

\section{Potential Environmental Benefits}

Food waste is the second largest component of the U.S. municipal solid waste (MSW) stream, comprising about 18\% of the total amount sent to MSW landfills. This computes to about 30 million tons of waste annually[15]. As such, the diversion of this organic component of MSW can serve to greatly reduce landfill loading rates and has a high potential of greatly expanding their service life. As food waste decomposes in landfills, it is typically degraded into both carbon dioxide and methane gas and emitted into the atmosphere. While some of these landfills have gas collection systems to control these emissions, MSW landfills, according to the Environmental Protection Agency (EPA), are not required to install these gas collection and control devices until the capacity of the landfill exceeds both
2.5 megagrams and 2.5 million cubic meters of space (as listed in EPA Title 40 Code of Federal Regulations Part 60 Subpart WWW). By the time (and if) these thresholds are ever reached, it is highly likely significant amounts of methane, a GHG about 21 times more potent than carbon dioxide, has already been released into the atmosphere[16]. As a result, the ability to capture and collect this methane produced from food waste before the waste is sent off to landfills provides a significant means of reducing our overall GHG emissions. Furthermore, since food waste comprises such a significant portion of the MSW stream, it makes sense to prevent its transport to landfills from a purely space conservation standpoint. It is a large and complex undertaking to appropriately site and operate landfills, and diverting any portion of the refuse being sent to them will increase their lifespan and specifically reduce those problems associated with the decay of the organic components disposed of, including odors and vector (or unwanted pest) attraction.

\section{Food Waste Anaerobic Digestion in Kombolcha}

This feasibility study is intended to expand upon a specific disposal option for solid marketplace generated waste in Kombolcha. Due to the Haitians' heavy reliance on wood charcoal for a cooking fuel, much of the western half of Hispaniola is deforested. Biodigestion can serve as a means to both produce an alternative cooking fuel, as well as serve as a way to reuse the $75 \%$ of the waste stream which is estimated to comprise of food cast-offs[17]. While the digestion of food waste can produce approximately four times the methane yield as pig slurry can[6], there are a number of important advantages involved with using pigs in the digestion process in Haiti. Perhaps the most important of these is the lack of expertise and training in $\mathrm{AD}$ operation. Most reference literature which discusses AD makes it very clear that once the digestion process becomes unstable, it is very difficult to ensure that the entire system does not go "sour." In other words, even with expensive monitoring equipment which can provide up-to-date readings on such variables as $\mathrm{pH}$, alkalinity and gas production rates, it is almost impossible to stabilize an anaerobic reactor which is starting to become unbalanced. In order to operate and maintain a steady and balanced food waste $\mathrm{AD}$, all food residuals used as a feedstock would need to be well-homogenized, contaminant-free, and lacking such things as bones and shells. These preparations for AD would either be energy or labor intensive. Since Haiti does not have an extensive electric infrastructure[18], it would seem unwise to propose a system dependent on electric pumps or motors. Also, due to the unlikelihood of a solid waste management operation providing enough revenue to pay a sizeable workforce, a system which is reliant upon the smallest number of workers possible would provide the best chances of a financially successful operation. Keeping these 
obstacles in mind, remembering the bacterial buffering capacity which manures provide, and considering that Haitians are familiar with pig husbandry already, the best proposal for an anaerobic digestion facility in Haiti would involve using swine to consume the organic portion of the marketplace waste stream and provide a homogenous, contaminant free feedstock in the form of pig manure.

\subsection{Case Studies}

(A) In Oakland, CA, there is currently a wastewater treatment operation run by the East Bay Municipal Utility District (EBMUD), which codigests food waste with their wastewater solids in anaerobic digesters. The EPA provided them with a grant to study the possibility of using pure pulped food waste as a feedstock for AD, and in March 2008 they released a report that provided very encouraging results from their bench-scale studies. These results included that for an equal amount of digester volume, food waste has the ability to produce up to three times the methane volume that wastewater solids can produce[19]. This is partially a result of higher energy content per mass, but also is due to the fact that food waste can be added to the digester at a higher loading rate (per volume) than wastewater solids. EBMUD further discovered that the solids deposition rate for food waste was less than that encountered for the digestion of wastewater solids. This fact could give AD facilities which used food residuals a cost advantage over those which would digest manures since the tipping fee for digester solids is often considerable. However, the opposite may be true if the digester sediment was thermally treated (say in thermophilic conditions) to the point where it could be bagged and sold as a soil amendment. The only other problem temporarily encountered by EBMUD was digester instability due to inversion heater failures. These failures produced digester instability and testing operations had to be restarted as a result. The published report highlighted the importance of keeping a stable operation temperature.

(B) Another example of successful food waste digestion is at the digestion facility in Anyang City, South Korea. This digester system can handle 15 metric tons $(\mathrm{mt})$ per day of food waste. While the waste is processed at an operational cost of U.S. $\$ 60 / \mathrm{mt}$, it is almost impossible to dispose of it at a landfill for the cost of $\$ 25 / \mathrm{mt}$ due to limited space. Originally, the plant ran into difficulties with their conveyor system due to bones and metal fragments, but these problems were addressed and everything is currently operational[8]. This system uses a two-tank design; one is used for acid digestion and the other is used for methane production and capture. One of the interesting aspects of this design is that some of the alkaline liquid from the methanogenic tank is circulated into the acidogenic reactor in order to ensure the $\mathrm{pH}$ of the acidogenic tank does not get too low. The acidogenic tank is also used as a means of further feedstock purification. As it is mildly agitated through stirring, floating plastics and other pieces of scum are skimmed of the top while ground up grit and other dense materials are removed from the bottom of the tank.

\section{Conclusion}

Food waste can serve as high methane-producing feedstock for $\mathrm{AD}$ if it is properly pretreated and the digester is carefully operated. However, before construction of such a system, it is important to characterize the potential waste stream and determine the cost and amount of energy needed for proper pretreatment and operations. Also, a financial study of the different tax incentives, utility power buyback rates, local and federal government grants, carbon credit prices, and biosolid treatment regulations and markets should be performed. Different systems will likely need to be determined and developed on an individual waste stream basis. It is recommended that a pilot-scale facility be tested to determine the digestion process which works best prior to full-scale construction, especially considering that there currently is no commercially-operated food waste AD in the United States. For Ethiopia and developing countries, due to lack of financial, educational, and material resources, it is probably best to focus on a more stable feedstock such as pig or some other animal manure for possible AD units. People in developing countries are typically part of a more agrarian society where animal caretaking and consistent manure collection are familiar practices. It is no great step to collect this manure and dilute it by a constant amount before input into a digester. However, having to constantly adjust a food dilution rate because of an inconsistent food waste stream can prove problematic even to people who have experience with anaerobic systems. Regardless, individual opportunities need careful assessment and all feedstock options should be considered both individually and comingled to find the best system.

\section{References}

[1] Gerardi, Michael. The Microbiology of Anaerobic Digesters. Hoboken, N.J.: Wiley-Interscience, 2003. eBook.

[2] Li, Yebo, Stephen Park, and Jiying Zhu. "Yebo Li *, Stephen Y. Park, Jiying Zhu." Solid-state anaerobic digestion for methane production from organic waste 15. (2011): 821-826. Web. 26 Nov 2010.

[3] Viessman, Warren, Mark Hammer, Elizabeth Perez, and Paul Chadik. Water supply and pollution control. Prentice Hall, 2008. Print.

[4] McCarty, Perry. "Anaerobic Waste Treatment Fundamentals." Public works 95.9-12 (1964): n. pag. Web. 19 Nov 2010.

[5] Georgacakis, Dimitris, M. Sievers, and E.L. Iannotti. "Anaerobic Waste Treatment Fundamentals." Agricultural Wastes 4.9-12 (1982): 427-441. Web. 17 Nov 2010.

[6] Steffen, R., O. Szolar, and R. Braun. "Feedstocks for Anaerobic Digestion." Institute for Agrobiotechnology Tulln (1998): n. pag. Web. Nov 12010. $<$ http://www.adnett.org/dl_feedstocks.pdf $>$.

[7] Baron, Samuel. Medical microbiology. 4th ed. Galveston, TX: Univ of Texas Medical Branch, 1996. eBook. 
[8] "Technical Brochure \#66 - Food Waste Disposal Using Anaerobic Digestion." CADDET. CADDET Centre for Renewable Energy, 1998. Web. 25 Nov 2010. $<\mathrm{http}: / /$ www.caddet-re.org/assets/no66.pdf $>$.

[9] "Anaerobic Digestion Feasibility Study." Iowa Department of Natural Resources. R.W. Beck, June 2004. Web. 25 Nov 2010.

$<$ http://www.iowadnr.gov/waste/policy/files/bluestem.pdf $>$.

[10] Jaworski, Carole. "UF Helps Animals Get Leftover Treats From Theme Parks and Restaurants." University of Florida News. University of Florida, 25 Nov. 1997. Web. 19 Nov 2010. <http://news.ufl.edu/1997/11/25/food/>.

[11] Uhlar-Heffner, Gabriella. "Seattle Studies Anaerobic Solution for Source-Separated Food Residuals." Biocycle 44.12 (2003): 39-40, 42. Web. 19 Nov 2010.

[12] Current Organic Waste Digestion Project Protocol." Climate Action Reserve. California Climate Action Registry, 07 Oct. 2009. Web. $25 \quad$ Nov 2010 $<$ http://www.climateactionreserve.org/how/protocols/adopte $\mathrm{d} /$ organic-waste-digestion/current/>.

[13] Serve to Preserve." Renewable Energy Tax Incentives. Department of Management Services - State of Florida, 2010. Web. 25 Nov 2010.

[14] Jewella, William, Robert Cummings, and Brian Richards. "Methane fermentation of energy crops: Maximum conversion kinetics and in situ biogas purification." Biomass and Bioenergy 5.3-4 (1993): 261-278. Web. 25 Nov 2010.

[15] Turning Food Waste into Energy at the East Bay Municipal Utility District (EBMUD)." Region 9: Waste Programs. Environmental Protection Agency, 26 Aug. 2009. Web. 26 Nov 2010. $<$ http://www.epa.gov/region9/waste/features/foodtoenergy/f ood-waste.html>.

[16] Landfill Methane Outreach Program." EPA Home. Environmental Protection Agency, 13 Oct. 2010. Web. Nov 2010. http://www.epa.gov/lmop/basic-info/index.html\#a02.

[17] CHF International. Haiti Emergency Solid Waste Collection, Landfill Rehabilitation and Jobs Creation Program (SWM). (Cooperative Agreement \# 521-A-00-04-00028-00). Final Report (July 282004 - April 30, 2005). Silver Spring, MD: CHF International, August 15, 2005.

[18] Rehabilitation of the Electricity Distribution System in Port-Au-Prince - Supplemental Financing." Document of the Inter-American Developmental Bank. Inter-American Developmental Bank, 2010. Web. 26 Nov 2010. $<$ http://idbdocs.iadb.org/wsdocs/getdocument.aspx?docnum $=35294747>$.

[19] Gray, Donald, Paul Suto, and Cara Peck. United States. Anaerobic Digestion of Food Waste. East Bay Municipal Utility District, 2008, Web. 19 Nov 2010. $<$ http://epa.gov/region9/organics/ad/EBMUDFinalReport.pd f>. 